\title{
Chanting as mathematical enculturation
}

\author{
Anne Watson \\ University of Oxford \\ Email: anne.watson@educational-studies.oxford.ac.uk
}

\section{Introducing Assessment}

Unison response is a major teaching strategy in mathematics throughout the world. The spoken word is the dominant source of mathematical stimulus, the dominant shaper of the mathematical environment in which school learners construct mathematical meaning. The teachers' utterances are intended to be expert, and the creation of learner responses is intended to involve learning of some kind. This paper is intended to offer theoretical considerations, based on experience and observation of interactional routines in classrooms rather than on imagination or thought-experiment, which may lead towards a more developed theory of the roles and effectiveness of unison responses in mathematical learning.

The word 'unison' is used to describe situations in which learners say the same thing at the same time; often this has rhythmic, semi-conscious qualities in which case it can be described as 'chanting'. I use the word 'chorus' interchangeably with 'unison' although it also has Greek roots relating to the provision of narrative during the action of a play. 'Routine' is used to describe patterns of interaction which have become habitual through regular use; these may or may not involve unison elements.

\section{Examples}

Here are two contrasting examples of chorused response.

\section{Example 1}

The teacher showed learners how to multiply two binomial expressions in brackets to make a trinomial. As the teacher wrote the terms of the product she recited phrases loudly and slowly, leaving pauses where all learners were expected to insert words in unison.

Teacher: the first multiplied by the first

gives the

Learners: first term

Teacher: and the first multiplied by the second gives the

Some learners: second term
Teacher:

and the second multiplied by the first gives the

Some learners: third term

Teacher: $\quad$ and the last by the last gives you the

Learners: last term I cannot be sure that all learners were answering for the first and last terms, but it sounded like strong unison response. There was a noticeable difference between the loud, confident, bright sound of the first and last responses and the less secure, lower tones of the middle two responses. No other ways to think about this equivalence were offered in this lesson, no diagrams and no numerical examples.

I was able to see the work learners did on their exercises after these interactions. For many learners the order in which terms were multiplied was not a problem: they knew what they needed to do but not necessarily how to do it. I had an impression that even many of those who did not join in the middle part of the chorus knew which pairs of terms to multiply to get the middle terms. Reasons for getting the wrong answer were more likely to be errors in multiplying, especially where there were negative signs, or attempts to combine unlike terms in the product. This latter error made me wonder if they understood the word 'term' in algebra. Confusion between long-term, short-term, school term and algebraic term is an example of difficulties with ambiguity in the mathematical register (Pimm, 1987; Tobias, 2003). I also found myself asking 'what do you know about minus signs?' and they would immediately say 'two minuses make a plus' but could not necessarily apply this. The exercise required several manipulative subprocedures which learners had apparently shown competence in performing in the past, but which were not being brought into play automatically where it was appropriate.

\section{Example 2}

Learners were asked to count down from 100 in steps of $19 / 10$. To an observer it was clear that they were used to being asked to do such things, because they immediately became quiet, some of 
them closed their eyes, others looked down at their desks as if what they needed was written there, others mouthed the first two answers to each other silently. After several seconds of thought the teacher signalled them to begin chanting answers in unison. Why not try it yourself before you read on?

As they proceeded some smiled and the speed increased until the rhythm they had created suddenly broke down. If you have tried this yourself you will know when and why this happens. This cycle of speeding up rhythmically and then having to slow down and rethink happened a few times (how many times?) and eventually the teacher stopped them (they were into negative numbers by this time), and asked them to report on where they found it difficult and why. Some of their reports were about relationships within the structure of numbers; others were about the process of chanting in unison.

The teacher then asked them to spend a few minutes working on fraction questions which arose for them about the exercise, and they did so, discussing their answers and calculations and observations with each other in small clusters. Some of them were trying the same kind of exercise with different constant differences.

In this kind of classroom, where learners can talk openly about their chanting experiences, it is common to hear remarks such as:

I wasn't sure whether I was saying things with the others or a split second afterwards

I kept getting lost and used the others to get back in

I couldn't think quickly enough when things got hard, but it didn't matter because I could use other people's thinking

I was amazed at how quickly I could do this but now I want to check whether we were right

Chanting has not guaranteed learning, and the particular answers are not important in themselves, but the experience has given learners something to explore.

Critics of over-reliance on chanting, while recognising the need to provide ways to memorise mathematics, point to a model of passive learning which is implied and a lack of understanding which would result. In the second example this is clearly not the case. Although there are sequences of apparent passivity, the story is much more complex than a simple distinction between apparent passivity and activity.

\section{Oral traditions}

Mathematics is not a subject which has a strong oral tradition. It is passed on mainly through text, teachers and the experience of working on mathematical questions and problems at every level. Teachers and textbook writers mediate knowledge through verbal, graphical and symbolic routines. At its most mundane it is learnt by repeated exercising in order to become fluent with techniques; the learner has to remember what to do. There are ways to support this recall by learning facts and instructions by rote, but it is a fallacy to thus equate rote-learning with an oral tradition. Yet mathematics does, through the way it is taught, have moments of oral universality. In the English-speaking world, everyone has heard 'times the top by the top and the bottom by the bottom', or 'the square on the hypotenuse ... etc.', but these fulfil the role of universally known pneumonics rather than cultural tradition.

An oral tradition stimulates intellectual and social development: proverbs and riddles are used to develop reasoning power; stories about behaviour contain information about cultural norms and expectations and provide help to resolve dilemmas; word games 'strengthen' memory; rhymes encourage counting and the use of number words (Reagan, 1995). Memory of the stories permits their recall; remembered words can be brought into conscious use when appropriate to inform future action. "A purely oral tradition knows no division between recollecting and doing" (Illich and Saunders, 1988: 15). Memorised phrases provide the raw material for thought and discussion.

Why bring 'oral tradition' into the discussion of mathematics classrooms? Because there are features of the mathematical canon which could parallel all of the oral genres described above by Reagan, but we cannot go far in that direction without the need for written symbolism rather than just the spoken word. What this alignment shows is that mathematics does have its own rich and complex culture, and while learners need to acquire props to give them access to the culture, learning is the experience of using the props to resolve problems rather than their acquisition. What I see in classrooms, however, is reliance on oral interactions for a variety of low level reasons which fail to engage learners with the most important part of oral enculturation: the use of shared oral experience to promote thought, 


\section{Chanting as mathematical enculturation}

discussion, resolution and the development of a mathematical culture.

While so many classrooms in the world lack textbooks, it is naïve of mathematics educators to reject rote-learning, that is learning text so that it can be recited word-for-word, as an educational tool since at the very least it gives access to material for later consideration.

Reghi et al (1991) compared the effects of rotelearning among Asian learners and conceptual learning among Australian learners, testing both groups for their understanding. Their results revealed that a combination of rote-learning and thoughtful repetition of the learnt words, used by the Asian learners in their study, leads to deeper understanding than 'reading for understanding' alone. It seems that several oral repetitions of the text, each with a different focus on the content, help develop deep, structural knowledge rather than just mechanistic recall (Marton and Booth, 1997). What is puzzling here is why rote-learning should be done at all by literate learners who can always have access to written text. It seems to be seen by learners to resolve a perceived need to acquire surface knowledge which can then be used easily in tests, brought into use in new contexts where needed, and worked on in future to develop deeper knowledge.

The relationship between repetition and rotelearning is therefore two-way. Repetition of a thoughtful, attentive kind is required if rotelearning is to lead to deep learning, but repetition of words, possibly at a more superficial level, is also the mechanism for learning by rote. Recall of the songs and playground chants of childhood is easy, and their acquisition was often effortlessly achieved by listening to and joining in with others. Repetition, particularly when there is no access to books, is therefore an important cultural requirement for learning, both for acquisition of the words and for returning to them again and again to develop deeper understanding.

In the passage above I am guilty of not distinguishing between rote-learning and chanting. The chanting I have heard in classrooms is sometimes a mechanism for rote-learning, but not always, as I shall show. Similarly, it is not a mechanism which ensures understanding.

\section{Unison responses in a variety of classrooms}

In this section I am going to describe many examples of the use of unison responses in classrooms and examine the learning opportunities they offer learners. Several of these occurred during enquiry into interactional routines in South African classrooms. As an outsider I observed nineteen secondary mathematics lessons, containing between 40 and 50 learners each, taught by thirteen teachers in four urban schools. Classes ranged from year 8 to year 12. Two of the schools were under-resourced and had some teachers who voluntarily described themselves as having very low morale. One of the schools had a more stable history, with learners from a wide range of social backgrounds and well-qualified teachers. These three were township schools. The fourth school was formerly European mono-cultural and was well-resourced. The sample was completely opportunistic. In addition, the willingness of teachers to have me in their classrooms suggests that they were confident practitioners showing me their best practice.

I had field notes of all the interactional routines which included the expectation of whole-class unison response used in these lessons. I analysed them to identify possible purposes, to conjecture about the learning opportunities they offered to learners, and to imagine ways in which they might fail in their purpose. My claim is not that these were the actual purposes, the actual learning or the actual failures. Rather it is to discuss the issues which were raised for an informed observer, with professional and academic perspectives, which might then frame future research.

The possible purposes I identified were:

Recall of words or concepts

Instructions

Reasoning routines

Commentary

Participation

These categories are not exclusive, and there may be other ways to categorise such routines, but they did encompass everything I saw. I see them as tools for further thought, rather than a definitive frame for future work.

\section{Recall of words or concepts}

Teachers use unison routines both to generate, and to remind learners of mathematical facts. For example, the teacher says:

a square must have four equal

The sentence must end with a noun, so choice is limited and most learners say "sides" immediately. The emphasis seems to be on the syntactic structure rather than the four-ness or equality involved in squares. Compare this to another version in which the teacher says:

a square must have

and learners say: 


\section{Anne Watson}

four equal sides

Response in the second case was less united and several learners were silent as they were not being prompted to recite a well-known phrase. Possibly some learners were silent because they did not know which of several possible answers would be deemed correct. More likely they were waiting for clues or cues about what to say. The second response requires some knowledge of concepts; the first requires a limited level of classroom norms and linguistic cadence, knowledge of words would be enough.

Another familiar example is the recitation of "vertically opposite angles are equal". It is hard to understand 'vertically' in this context, which relates to 'vertex'. Without this Latin root or some other contact with a Latinate language, how can 'vertically' make sense for learners? The normal meanings of 'opposite', such as 'living opposite me' or 'the opposite team', even 'opposite angles of a quadrilateral', do not quite contain the meaning of 'opposite' in this phrase. We ought to assume that 'angle' is understood, although if learners believe, as many do, that the size of an angle is related to the length of the lines delineating it, this will be a confusing statement. Finally the word 'equal' does not give you an instruction, it is a statement of a relationship. An alternative version of this could be the instruction 'equate vertically opposite angles'. What is a learner to do with this phrase? It does not tell you what to do and is full of confusing words.

Taking time to develop this understanding of the phrase is important, as Zevenbergen (2000) and Tobias (2003) suggest, but even knowledge of what it means and how it can be used is no good if you cannot find the vertically opposite angles in a diagram because they don't look like the ones in the teacher's diagram. Knowing the words is only a tiny part of understanding what the words are about; understanding includes knowing how and when to use the property.

The first kind of routine was observed frequently, but seems unrelated to conceptual understanding. The second kind was seen less frequently but seems to invite more engagement with meaning as well as words.

\section{Instructions}

Teachers use unison response in gap-filling routines to instil, through repetition in several situations throughout their school experience, rules about how to do mathematics. For example, a teacher says:

what we do to one side we do to the and the learners finish the phrase by saying: other

In this case the whole phrase has not been said by the learners, they have merely finished a linguistic structure with an obvious response.

In another example, the teacher says: what do we do with two minuses?

and learners answer: two minuses make a plus

This is intended to provide an inner monologue to tell learners what to do, but it is well-known that such a monologue is often applied in inappropriate circumstances, such as " $-2-3=+5 "$. In the algebra example at the start of this paper, we saw that learners do not necessarily recall it when appropriate. These phrases are merely tools, and, without explicit work on how they can be used in contexts, they can have an effect on mathematics like random hammering.

Imagine a teacher then asking learners to create questions in which the phrase might be useful, and offering examples of where other learners have misapplied the rule. In this case the remembered rule becomes attached to an exploration of where it is, and where it is not, useful. Memorised phrases, as in profound oral traditions, are used as the raw material for contemplation and deepening understanding, but in many mathematics lessons such phrases can be seen as a meaningless instruction or as an endpoint in themselves.

\section{Reasoning routines}

Unison responses can appear to engage learners in sequences of mathematical reasoning. For example:

Teacher says: If it isn't positive it must be

Learners respond: Negative

The teacher models how she hopes learners will think, but this line of reasoning is mathematically oversimplistic; it ignores zero. Chorused phrases often have a symmetry which is interrupted by special cases!

To use this reasoning routine the pupil needs to know when she should consider signs and hence bring the routine into play. As with instructional routines, learners need to know when and how to use them. Also, in this case, the learners have only supplied the missing linguistic opposite and may not connect this gap-filling activity with mathematical meaning at all.

A more complex example of this was demonstrated with a class which was working on a problem involving angles in a circle. On the board was a 'toolkit' of diagrams illustrating angles in 


\section{Chanting as mathematical enculturation}

the same segment (called 'the butterfly'), a cyclic quadrilateral, and the alternate segment theorem. The teacher points to the diagram given with the problem and says:

Does this look like a butterfly?

$$
\text { Learners say: No }
$$

Does this have any external angles? Learners say: No

So it must be about cyclic quadrilateral Learners say: Yes

Again the teacher is offering a model for reasoning, a way to go about answering examination questions. There is no guarantee that learners are making the active choices which the teacher intends through just responding with "No" when it seems sensible to do so, as in ritual speech (Pimm, 1987: 73); learners recognise a linguistic routine and give a well-known response. Just as in the previous example it is interesting to look for what is missing here. There is no 'angle in a semicircle' tool offered, nor the possibility that the circle is a red herring and the question might be resolved using angle properties of general quadrilaterals alone. However, as a model of gathering what you know and relating it to what you are given and what you want (Mason et al, 1982) it provides a general heuristic which the teacher uses frequently and hopes the learners will adopt. Thus it could be providing scaffolding for learners to become more able to engage in a mathematical reasoning routine.

What seems just as likely, however, is that learners are merely picking up clues from the teacher's intonation and the knowledge that he will go through all the unhelpful possibilities available, one at a time, coming to the correct one last. This, of course, is not a useful reasoning routine because it depends on knowing the outcome!

\section{Commentary}

Teachers often ask learners to join in a commentary as they work through an example on the board. Learners who provide their own commentary while reading through worked examples appear to learn with more understanding than those who merely look for a template or pattern into which they can fit different numbers (Anthony, 1994), so the aim of developing a commentary is well-founded. (It also, incidentally, coincides with the use of 'chorus' in Greek plays to mean the use of narrative to elaborate on the action.) But in many cases I saw of this, learners were only invited to comment on mundane steps. In one case, the teacher was demonstrating algebraic substitution and did not invite any participation until she got to "seven from four..." to which learners responded "you can't". This was a minor aspect of the whole piece of work (and one could question whether "you can't" is a correct or helpful mathematical answer at secondary level). Another example concerned the calculation of the area of a shape made up of rectangles; learners were not invited to respond until the teacher got to "three times four is ...?" when they were invited to complete the story by saying "twelve". I saw no examples of learners being invited to join in the commentaries on central conceptual or reasoning aspects of a worked example in unison, and it is hard to imagine how this would work, since learners make their own sense of what they see and there is no reason to suppose that unison response would be at all possible. Nevertheless, where there were learnt routines or arithmetical aspects to the work, learners sometimes joined in together to say what was being written or performed.

\section{Participation}

Some of the examples given above require so little from learners in terms of mathematical engagement that I began to wonder if the main function is social participation rather than enculturation into mathematical activity. Seen as social participation some of the examples above make more sense.

With quite an advanced class, finding the coordinates of a point of intersection, a teacher says:

This bracket gives us the $\mathrm{x}$-coordinate of one of the points and this bracket gives us the $\mathrm{x}$ coordinate of the

and the learners respond: other

The learners are not involved in the reasoning; they merely follow familiar word rhythms to supply the end of a sentence, as they have done in every mathematics lesson. They would rarely have to reproduce this bit of reasoning for themselves as it is specific to a very small subset of problems they may meet. The likelihood that when they do need it they will think to use it as a recalled routine is very small, yet the unison response gives the impression of mathematical engagement and provides the teacher with feedback from which she can draw confidence.

Unison response has, as I have tried to show, tremendous potential to engage learners in cognitive activity, but seems often to be reduced to mundane or social uses and even its potential for supporting the learning of useful text by rote is underexploited. 


\section{Anne Watson}

Chanting for engagement and awareness The research above is reported more conventionally in Watson (2002), but my thinking has developed since that publication. Awareness of subtle differences in oral routines led me to 'collect' more examples. In particular, as in Example 2 at the start of the paper, I looked for uses of chanting which went beyond mundane aspects of mathematics and which provided the learners with some raw material for future work. By looking at these I saw that unison responses have a strong social purpose in that they give learners a role to play in the mathematics lesson, but they go beyond this. They also enculturate learners into relating words and mathematical structures and into participating in other mathematical practices, rather than just classroom practices. They also use voice as a mechanism for generating physical engagement in mathematics, sometimes supplanting mental engagement.

\section{Chanting to relate words and mathematical structure}

The example of counting-back given at the start of the paper uses a relationship between number structure and rhythm to generate knowledge of, and interest in, fractions. An easier and much more common example of this is the chanting of the eleven times table. Because of the rhythm, we could all say that 'tum elevens are tumty-tum; plonk elevens are plonky-plonk' even though these make no mathematical sense, but we could also say that 'twelve elevens are twelvty-twelve' - and indeed they are. The rhythm mimics the numerical structure and the relationship between 'twelvtytwelve' and ' 132 ' is worthy of mathematical exploration. If all that happens is that the teacher stops the chanting at 'nine elevens' a valuable opportunity to learn about number has been lost.

In a video, Dave Hewitt teaches a lesson on 'doing and undoing' as a metaphor for solving linear equations (Open University, 1992). At one stage he sets up a unison response similar to this:

Teacher: if I added 5, I subtract

Learners: 5

Teacher: if I added 19.2, I subtract

Learners: 19.2

Teacher: if I added c, I subtract

Learners: $c$

Teacher: if I added 'three-pi-squared' I subtract

Learners: three-pi-squared

Teacher: if I added alpha, I subtract

Learners: alpha
In this lesson there are other sequences in which subtraction as 'undoing' adding is emphasised; the point of this sequence is partly to enculturate learners into the range of possible mathematical objects they may encounter, so that their experience of constant terms in equations is not restricted to small integers. This kind of reminder is repeated in other lessons every now and then. The rhythm emphasises that they can all be treated in the same way as more familiar numbers and reminds learners of the oppositional pairing of addition and subtraction. The intense repetition over a short period of time may be more effective in instilling the oppositional pairing than irregular repetition spread thinly throughout several lessons.

\section{Chanting for multiple sensory contact with mathematics}

In a lesson about expanding brackets, a Jamaican teacher, Ceva Macpherson, wants learners to meet the expansion of $(a+b)^{2}$ and to at least be aware that it is NOT $a^{2}+b^{2}$, a common error. But the lesson achieves more than this; it provides an image which, for those who can work mentally with spatial images, gives access to what the expansion really is. The lesson starts with manipulation of shapes and description of the results in terms of conservation of area, building up to:

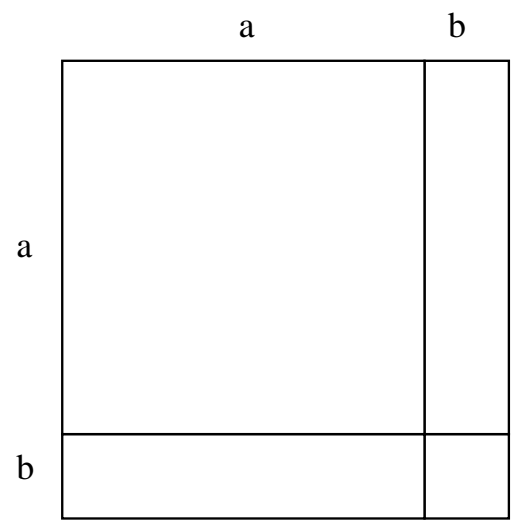

Thus, as long as learners know the area of rectangles, and are happy with conservation of area, and understand that it is area they are finding, they construct the algebraic representations for themselves. They share their ideas and the class reaches agreement about the equivalence. But the lesson is not left there. They then chant and dance, to the Jamaican anthem 'One love, One heart', that ' $a$ plus $b$ squared $\ldots$ is $a$ squared plus $b$ squared plus $2 a$ times $b$ ' rhythmically many many times. Choice of an unfamiliar tune would give more to remember, not less. The choice of the anthem is 


\section{Chanting as mathematical enculturation}

important as it is known and loved by everyone, it is a common heritage and binds them socially and culturally. At the end of this experience it is less likely that anyone will omit the final term after the $a^{2}+b^{2}$ because they would recall that the chant continued in a certain way. They may not recall WHAT the missing item is, but recalling the chanting itself might trigger a return to the spatial memory to reconstruct it. Chanting is used to develop memory of mathematics which has already been understood through other senses; visual, oral, musical, verbal and physical experience combine with the symbolic representations.

In these examples of effective chanting, a move from listening, thinking and consciously repeating to the automatic, rhythmic, mantra-like states of chanting has been deliberately invoked in order to engage learners subconsciously with mathematics.

\section{Chanting as talking mathematics}

Raj Varma's lessons in the UK are carefullyconstructed journeys through complex structures of mathematics, with a focus on understanding. In a lesson on multiplicative reasoning he spends a great deal of time getting learners to distinguish between fractions which are greater than one and those which are less than one. It is important to take time over this because many learners will have images of fractions as parts of pizzas rather than numbers of any size, and he intends eventually that they should be able to predict whether multiplying by a particular fraction will increase or decrease a quantity. His lessons include unison gap-filling routines and the development of rhythms of words which relate to structure, such as I have already described.

But he also gets whole classes of learners to repeat phrases which have no rhythm to them, such as: "if the numerator is greater than the denominator, the number is greater than 1: if the denominator is greater than the numerator, the number is less than 1'. Learners cannot just open and close their mouths in the right place, the sentence is too complicated for that. Guessing what the words will be is hard, there are too many distinctions to make. Indeed the phrase draws attention to the fact that there are distinctions to be made between numerator and denominator, and between greater and less than 1. Rhythm is not a big feature of this repeated phrase; to do it correctly you have to be engaged with meaning to a certain extent and get the distinctions right. This is not the kind of unison response which aims for subconscious automatisation of mathematical knowledge; it aims to promote conscious awareness of complexity. If nothing else, those engaging in this lesson might later recall that there is something you have to think about when multiplying by fractions, that fractions can be seen as 'numbers', that the words 'numerator' and 'denominator' are worth knowing better, and that lexical density is a feature of mathematics (Halliday \& Martin, 1993). Learners gain familiarity with the mathematical register by connecting technical terms loosely with partly understood concepts in the same way as someone who learns a song in a new language might later understand its meaning and, indeed, refine their knowledge of the words.

In subsequent interactions in the classroom Raj asks learners to repeat the phrases individually when offering solutions or methods, modelling the kind of thinking he hopes they will all do silently in future. Thus he supports learners in linking what they said in unison to what they might think on their own. He claims, and his learners and colleagues corroborate this, that saying things in your own voice helps 'fix' them, and the complexity of what he asks them to repeat forces them to think more about what they are saying. In such lessons, unison response is used for particular purposes within a more complex teaching situation, not as a method of transmitting knowledge. It might be helpful to distinguish between chanting, which implies automatisation of speech so that subconscious relationships can be made, and unison response in general, which includes chanting but also allows the highly conscious activities generated by Raj.

\section{Conclusion and a research agenda}

Pimm (1987) says that there is

... a deep-rooted belief on the part of many teachers that there is a power in someone saying things aloud, and therefore it is better for the learners to say the central part for themselves, rather than merely hear it expressed by the teacher (p. 54).

In the examples above we have seen several manifestations of this belief, not all of which appear to benefit learning. A superficial understanding of the role of recitation in learning is demonstrated in some routines, separating unison response from its place within oral traditions by detaching it from meaning, and failing to make use of the learnt words for critical examination, discussion and revisiting in different contexts. Furthermore, a sense that hearing one's own voice 
saying something makes it more likely to be retained can lead to emphasising retention of verbal sounds as the only way to accrue factual and procedural knowledge.

In their desire to be understood, teachers can too easily identify chorus responses as feedback giving evidence of learning. More helpfully, they may believe that learned responses provide scaffolding for learners to develop appropriate inner monologues which are versions of the speech patterns offered by experts. Brodie (1989) points out that this process may be especially prevalent where learners are not learning in their first language. Only in Raj Varma's lessons, when learners are invited to say things individually, is any attention paid to those who do not fulfil the response 'correctly'; in other cases it seems to be assumed that being immersed in the chorus will eventually result, through enculturation, in full participation and correct recall.

There is very little which has been written about the use of unison response in the learning of mathematics, and in the professional arena it is common to reject it as an approach. However, it does not make sense to dismiss unison response as a poor teaching strategy simply because it is strongly associated with underachieving educational settings. ${ }^{1}$ Some learners do succeed in mathematics through being taught in typically unison classrooms. Further analysis from linguistic, psychological, educational and sociocultural perspectives would be beneficial, as would exploration of the following questions:

How can learners be helped to apply learnt phrases and ritual speech patterns meaningfully in their work? How can learners be helped to discriminate between appropriate and inappropriate applications of learnt phrases? How much use, and what kinds, of chorus response are purposeful? How have successful learners from classrooms where chorusing is a main teaching mode used their experience to achieve mathematical understanding? What ways can be found, particularly in under-

\footnotetext{
${ }^{1}$ Recently it has been widely promoted in the UK through official channels, including the distribution to all school mathematics departments of videos of Raj Varma's teaching, and David Hewitt's teaching to teacher educators of all subjects.
}

resourced classrooms, to relate learnt phrases to other representations of their mathematical meanings?

\section{References}

ANTHONY, G., 1994, "The role of the worked example in learning mathematics" in Jones, A. et al., eds, SAME papers, Hamilton, NZ: University of Waikato

BRODIE, K., 1989, "Learning Mathematics in a Second Language”, Educational Review 41(1), pp. 39-53

HALLIDAY, M. \& MARTIN, J., 1993, Writing science: literacy and discursive power, London: Falmer

ILLICH, I. \& SAUNDERS, B., 1988, The Alphabetization of the Popular Mind, London: Marion Boyars

MARTON, F. \& BOOTH, S., 1997, Learning and Awareness, New Jersey: Lawrence Erlbaum

MASON, J., BURTON L. \& STACEY K., 1982, Thinking mathematically, London: Addison Wesley

OPEN UNIVERSITY, 1992, EM236 Learning and teaching mathematics. Milton Keynes: Open University

PIMM, D., 1987, Speaking Mathematically: communication in the classroom, London: Routledge

REAGAN, T., 1995, "Language and Skills or Oracy in Traditional African Education", Journal of Research and Development in Education 28(2), pp. 106-112

REGHI, M., ASTILLA, E. \& WATKINS, D., 1991, "The- Asian-as-a-rote-learner stereotype: myth or reality?", Educational Psychology 11(1), pp. 21-34

TOBIAS, B., 2003, "Do you speak mathematics?", Pythagoras 58, pp. 21-26

WATSON, A., 2002, "Use of Unison Responses in Mathematics Classrooms", in Winter, J. and Pope, S., eds, Research in Mathematics Education Volume 4: Papers of the British Society for Research into Learning Mathematics, pp. 35-49, London: British Society for Research into Learning Mathematics

ZEVENBERGEN, R., 2000, "Cracking the code' of mathematics classrooms: school success as a function of linguistic, social and cultural background", in Boaler, J., ed., Multiple perspectives on mathematics teaching and learning, pp. 201-224, London: Ablex 